\title{
Developing Nursing Capacity for Health Systems and Services Research in Cuba, 2008-2011
}

\author{
Nelcy Martínez MPH
}

\begin{abstract}
INTRODUCTION Health systems and services research by nursing personnel could inform decisionmaking and nursing care, providing evidence concerning quality of and patient satisfaction. Such studies are rather uncommon in Cuban research institutes, where clinical research predominates.

OBJECTIVE Assess the results of a strategy implemented between 2008 and 2011 to develop nursing capacity for health systems and services research in 14 national research institutes based in Havana.

METHODS The study comprised four stages: description of approaches to health systems and services research by nurses worldwide and in Cuba; analysis of current capacities for such research in Cuba; intervention design and implementation; and evaluation. Various techniques were used including: literature review, bibliometric analysis, questionnaire survey, consultation with experts, focus groups, and workshops for participant orientation and design and followup of research projects. Qualitative information reduction and quantitative information summary methods were used. Initially, 32 nursing managers participated; a further 105 nurses from the institutes were involved in research teams formed during intervention implementation.
\end{abstract}

RESULTS Of all published nursing research articles retrieved, $8.9 \%$ (185 of 2081) concerned health systems and services research, of which $26.5 \%$ (49 of 185 ) dealt with quality assessment. At baseline, $75 \%$ of Cuban nurses surveyed had poor knowledge of health systems and services research. Orientation, design and followup workshops for all institute teams developed individual and institutional capacity for health systems and services research. Post-intervention, $84.7 \%$ (27) of nurses reached good knowledge and $14.3 \%$ (5) fair; institutional research teams were formed and maintained in 9 institutes, and 13 projects designed and implemented ( 11 institutional, 2 addressing ministerial-level priorities) to research nursing issues at selected centers.

CONCLUSIONS A systematic strategy to build nursing capacity for health systems and services research can be effective in involving nurses in such research and in developing institutional support for it, fostering compliance with Cuban and international professional development priorities for nursing, as well as contributing to quality of patient services.

KEYWORDS Health systems, health services, health services research, evaluation studies, intervention study, nursing education, nursing, capacity building, Cuba

\section{INTRODUCTION}

Public health has been defined as the science and art of preventing illness and disability, prolonging life, and promoting physical and mental health through society's organized efforts.[1] Its primary objective is to improve the health of populations, and it does so through essential functions described by $\mathrm{PAHO}$ [2] as competencies required of health systems to achieve this goal. These functions are defined as the set of actions required to meet specific targets, in turn necessary to achieve the overarching population health objective. They should be viewed as both emerging from social practices and having as one of their main purposes the promotion and reinforcement of healthy social practices.[2]

The essential function of health research is one of the competencies that must be developed by health systems. Frenk describes it as a field with two main objectives for analysis: epidemiologic study of population health conditions and study of organized social response to those conditions (in particular, how that response is structured in the health care system).[3]

Health research performance is variable in the Americas. One $\mathrm{PAHO}$ study indicated that most countries in the region did not have plans to develop health research and did not periodically evaluate their progress in fulfilling a program of essential health research; those that did so nevertheless failed to communicate results to relevant parties. There were deficiencies in interaction with researchers and dissemination of results to the scientific community, as well as disconnect between areas investigated and national priorities. Evidence also revealed that the region was weak in research on collective interventions and community health.[2]
Such deficiencies in the Americas underscore the need for strategies to develop and strengthen research capacities. To advance, interventions are required at three levels: training individual researchers, generating institutional capacity to carry out relevant research, and involving national health systems responsible for most policymaking.[4] Lansang added a supranational level.[5]

Intervening at an individual level in investigators' scientific and academic training implies development of research skills as such. Although this does not in itself guarantee quality of results-since these also depend on the trainee's personal disposition-it is the bedrock of researcher training.[5] The institutional level involves institutions positioning themselves as reference facilities in their areas of expertise, according to the potential of their human resource base. Researcher training at the first level is only sustainable if there is continued followup; the institutional level must offer incentives to young researchers, build teams and create the necessary research infrastructure. According to Nchinda, institutional development must ensure that all individuals with research aptitude have the opportunity to develop their skills.[6] At the health system level, research capacity building involves creating agencies to run national programs and define priority research lines. Good investigators in good institutions are useless without a supportive research climate, funding and means to communicate results-all health system functions.[3]

Outlining strategies to develop research capacity in the profession is a priority for international nursing organizations. In 2011, the International Council of Nurses published its strategic directions for the period 2011-2015, stating the need to upgrade nurses' 
skills for research aimed at improving quality of service delivery. It urged development of evidenced-based nursing, noting that a major obstacle is nurses' limited research skills.[7]

The search for evidence involves several types of research. If individual care is the issue, traditional clinical research conducted by most nurse researchers is adequate.[8] If, however, the goal is to provide evidence on how to improve service organization or advise government policy on regulation of the profession, then health systems and services research (HSSR) is needed, in which the object of study is "the system itself or any other components or inter-relations."[9] This is a path less often taken by nurses.[10]

Cuba's Ministry of Public Health (MINSAP, the Spanish acronym) has 15 Scientific-Technical Program Areas (Programa Ramal de Investigación, or PRI, the Spanish acronym), one of which is HSSR (PRISS, the Spanish acronym).[11] In 2008, PRISS reported that nursing was the health profession with the least capacity in HSSR since the program's creation in 1986,[8] a finding seconded by the Ministry's National Nursing Division (DNE, the Spanish acronym).[9] A search for information on the topic yielded no strategies for developing nurses' research skills in Cuba. A 2002-2005 project to promote HSSR in Cuba led by the National School of Public Health (ENSAP, the Spanish acronym) was an important contribution at the national level, but it did not involve nurses.[12]

There is no universally-accepted definition of what constitutes a strategy, but a common element in many definitions is identification of a gap between the current situation and the desired one, with objectives defined as well as actions to fulfill them. The desired situation for the strategy described here is for nursing professionals in Cuban research institutes to conduct HSSR.

The study objective was to implement and assess a strategy to develop HSSR skills in 14 Havana-based national research institutes-both individually among nurses and institutionally, with the formation of research teams-and the design of nursing HSSR studies to address problems identified in these institutions.

\section{METHODS}

An intervention study was conducted between 2008 and 2011 in 14 Havana-based national research institutes with nursing services. The study universe consisted of the institutes and their nursing managers.

Selection criteria, institutional Those in which research is central to their mandate: national reference centers in their specialties (contributing to replicability in the rest of Cuba); priority assigned by DNE to institute nursing research. Fourteen institutions were selected, with specialties ranging from cardiology to occupational health.

Selection criteria, individual According to the Alliance for Health Policy and Services Research, linking decisionmakers with the research process is important for ensuring that findings are put into practice.[13] Thus, purposeful sampling[14] was used to select senior nurse managers at the institutes (deputy directors for nursing, ward and other supervisors, or academic advisors) who had belonged to research teams in their institutes for more than three years. A total of 32 nursing managers who met criteria were selected; another 105 nurses were not part of the primary study sample but participated in research teams formed. Data on variables such as age, sex, schooling, and years of experience were not considered relevant and the study sample was not described beyond inclusion criteria.

Ethical considerations The MINSAP PRISS ethics committee approved the study, as did DNE and participating institutes' deputy directors for nursing. All participants gave written, informed consent. Findings will be used by DNE and institute deputy directors for nursing to provide followup on issues identified.

Study design A simple pretest/post-test quasi-experimental design was used, because the population was small, the baseline practically nil, and it was certain that participating institutes had no similar interventions capable of biasing results.

Conceptually, the study was divided into four stages, numbered by date of initiation (with some temporal overlap) (Figure 1).

Figure 1: Conceptual flow of intervention to build nursing capacity for HSSR, Cuba 2008-2011

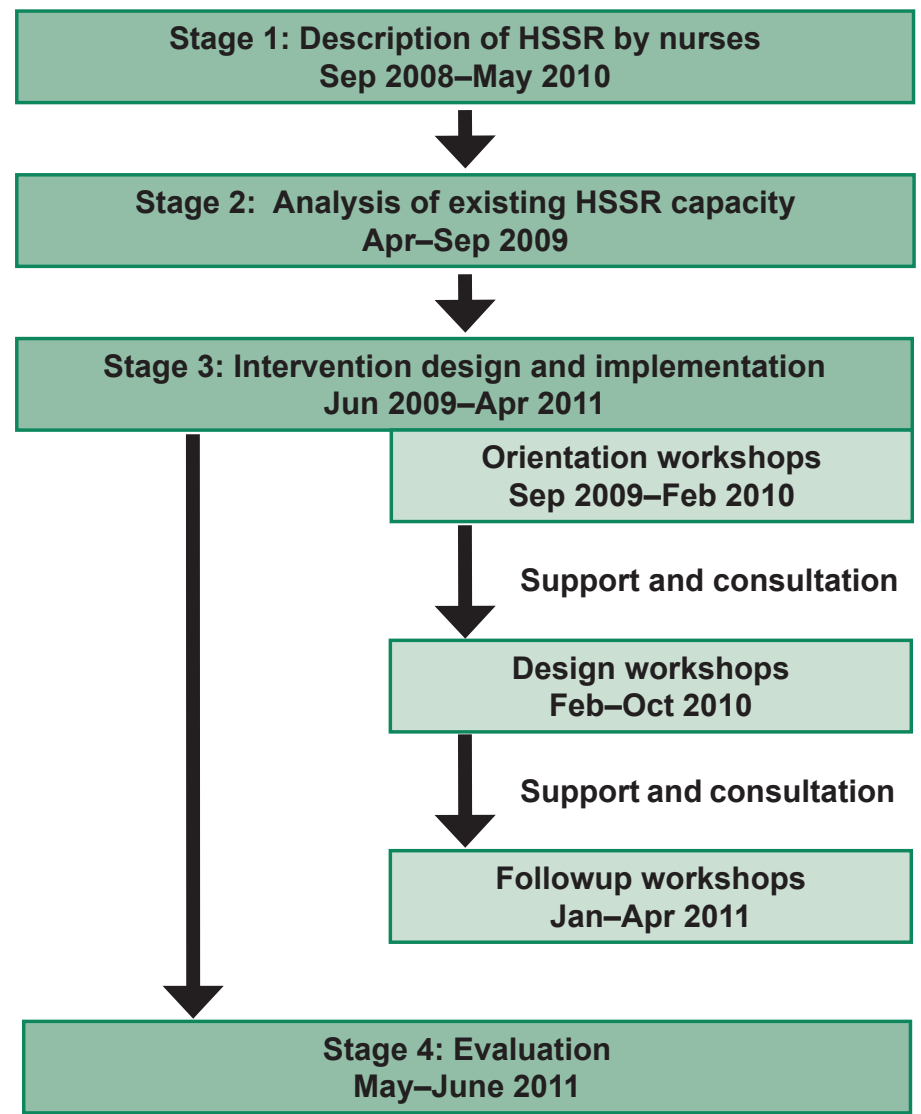

HSSR: Health systems and services research

Stage 1: Description of nursing HSSR (September 2008-May 2010). The objective of this stage was to ascertain characteristics of HSSR conducted by nurses in Cuba and internationally, using a deductive approach. For this purpose, a horizontal bibliometric study was employed of nine journals in which nurses periodically publish. Revista Cubana de Enfermería was used for analysis of Cuban publications. All research articles published between January 2000 and March 2010 were reviewed; articles describing HSSR were selected and classified according to whether or not they related to national PRISS research priorities. 
Eleven categories of research were identified: health situation analysis methods; health situation trends, policies, and strategies; nursing care costs; organization, structure and function of the health system, its institutions and services; technology assessment; access to and equity in nursing services; community participation and intersectoral action; nursing service quality; patient satisfaction with nursing care; nurses' job satisfaction; and nursing human resource management.

Articles identified as HSSR were read and classified in thematic areas by the principal investigator, and in more complex cases, cross-checked by two investigators. Data were tabulated, with percentages used as the summary measurement for analysis of the following variables: journal, articles published, publication thematic area and year of publication.[15]

Stage 2: Situation analysis of HSSR capacity (April-September 2009). The objective of this stage was to determine existing capacity relevant to the expected results, starting from the premise that individual capacities were linked with knowledge of HSSR and its design, while institutional capacity was defined by existence of research teams, selection of research topics, and results dissemination and application. Nurses' knowledge of HSSR was assessed, including variables pertinent to institutional capacity.

Two data collection techniques were used: an individual questionnaire and a focus group. Variables explored using both were: definition of HSSR, identification of research areas, participation in HSSR projects, results dissemination and application to decisionmaking.

Questionnaire Instrument content and format were validated by senior scientists who participated in and were recognized by PRISS as experts in their fields and were proposed by ENSAP and PRISS directors. In addition, they were required to have a doctorate in sciences; an academic rank of assistant, full or consulting professor; and at least ten years of experience in HSSR (principal investigator or project leader).

The ten participating experts were given a hard copy of the questionnaire and asked to determine question appropriateness for each operational definition to be explored. The second step in questionnaire validation was a pilot with 12 nursing managers in seven national institutions with similar levels of care and work dynamics to those of the study institutes.

Once validated, the questionnaire was used to survey the 32 professionals between April and May 2009. Individual item responses were classified as acceptable or unacceptable; overall knowledge was assessed as good, fair or poor. Overall knowledge was considered good if the respondent gave acceptable responses in all five areas explored; fair if responses were acceptable in four areas; and poor if they were acceptable in three or fewer areas. Each participant was assigned a code for comparison with responses to the same questionnaire administered following the intervention (questionnaire and scoring guide available from corresponding author).

Focus group A focus group was held in June 2009, following standard procedures.[16] Since focus groups require small numbers, participation was limited to one nurse per institute, for a total of fourteen. The moderator and observer were investigators with expertise in group techniques and familiar with the study participants. A topic guide derived from the questionnaire was used for the session, which lasted 90 minutes. A verbatim transcript was produced,[16] enabling initial theme classification and facilitating data synthesis and interpretation.[17] After interpreting and determining meanings and significance, the findings and discussion were compared with the theoretical framework and with research results found in the relevant literature.

Stage 3: Intervention design and implementation (June 2009April 2011). The intervention consisted of orientation, design and followup workshops described below. Information from the HSSR description and situation analysis was taken into account and the design validated by the experts.

Orientation workshops These workshops were held in each institute (doubling up in two instances) to familiarize nurses with HSSR and identify problems in nursing services that HSSR could address. Before the workshops, senior institute managers were asked to identify nurses with research potential (those with academic research training completed or in progress, or who had displayed interest and aptitude) who would compose the research teams to be formed. During the orientation workshop, deputy directors of nursing were asked to present a researchable problem inventory generated by institute nurses.

Themes addressed in the workshops included HSSR concepts, background and research areas; health research and nursing practice; and research project types, designs and phases. Participants received Cuban and international articles on topics covered in the workshop.[3,11,18-21] Workshop activities included introductions (of project, research team and participants), presentations, $Q \& A$ and discussion sessions, analysis of inventoried problems, and selection of research problem and team members. Based on the problem selected, each research team then had the task of elaborating the project profile: title, introduction, objectives and outline of methods. Virtual and in-person assistance was provided between workshops to address any questions that arose during the groups' work.

Design workshops A series of three workshops was held for institute research teams, with the objective of completing HSSR project design. In order to participate, research teams had to have developed the project profile as assigned in the orientation workshop. Thematic contents included PRISS background and main results during the period 2000-2010, the nursing HSSR situation in Cuba and internationally, types of HSSR and methods design, HSSR as evidence base for nursing care, theoretical and methodological bases for evaluation of nursing care quality, and the virtual community as a tool for HSSR development. Participants received Cuban and international articles on workshop subjects. $[18,22-24]$

Workshop activities included development of thematic contents; a session for $Q$ \& $A$ and discussions between participants and the capacity-building project team; project presentation and discussion; and a session to review methods and analyze projects presented. Suggestions were used to correct project designs for presentation at the next design workshop. As a final assignment, each team was required to submit their HSSR project to their 
institute's scientific committee and, once approved, begin implementation.

Followup workshops A sequence of three followup workshops was held, with participation by all research teams, to monitor and evaluate adherence to project timetables established in the design workshop. Activities included presentations of progress, adherence to timetables and preliminary research results.

Stage 4: Evaluation (May-June 2011). Results-based effectiveness evaluation with a simple pretest/posttest quasi-experimental design was used, since the aim was to evaluate the intervention's effects on HSSR capacity in participating professionals and institutes. We employed Zall and Rist, a 10-step model created to evaluate results of policies, programs, and intervention projects in different contexts.[25] Elements specific to this study are described below.

Selection and definition of expected results were arrived at by consensus among the DNE-the project's main client-institute nursing managers, research team members and experts. Indicators for expected results were: 1) Nursing managers achieve a satisfactory (fair or good) level of knowledge of HSSR; 2) institutes have nursing research teams to conduct HSSR; 3) nursing HSSR research projects are designed to study problems in institute nursing services; 4) nursing HSSR studies are approved for implementation by institute scientific committees; 5) nursing HSSR research projects are implemented on schedule; 6) nursing managers are involved in HSSR in their institutes; 7) nursing HSSR projects are approved in the national 2011 PRISS call for proposals; and 8) HSSR is discussed in scientific meetings and other events involving nurses. Targets set for results indicators are displayed in Table 1.

Responses to the questionnaire previously described were used for baseline data, along with a document review of research statistics from PRISS, the institutes and DNE. This questionnaire was readministered following implementation to evaluate the strategy

Table 1: Pre- and post-intervention indicators of nursing HSSR capacity, Cuba 2008-2011

\begin{tabular}{|l|c|c|c|}
\hline Indicator & $\begin{array}{c}\text { Pre-intervention } \\
\%(\mathbf{n})\end{array}$ & $\begin{array}{c}\text { Target } \\
(\%)\end{array}$ & $\begin{array}{c}\text { Post-intervention } \\
\%(\mathbf{n})\end{array}$ \\
\hline $\begin{array}{l}\text { Nursing managers with good or fair } \\
\text { knowledge of HSSR }\end{array}$ & $25(8 / 32)$ & 80 & $100(32 / 32)$ \\
\hline $\begin{array}{l}\text { Institutes with teams to develop } \\
\text { nursing HSSR }\end{array}$ & $0(0 / 14)$ & 50 & $64.3(9 / 14)$ \\
\hline $\begin{array}{l}\text { Institutes with nursing HSSR studies } \\
\text { designed }\end{array}$ & $7(1 / 14)$ & 50 & $64.3(9 / 14)$ \\
\hline $\begin{array}{l}\text { Institutes with nursing HSSR studies } \\
\text { approved by scientific committee }\end{array}$ & $7(1 / 14)$ & 50 & $64.3(9 / 14)$ \\
$\begin{array}{l}\text { Institutes with nursing HSSR studies } \\
\text { implemented per timetable }\end{array}$ & $0(0 / 14)$ & 50 & $64.3(9 / 14)$ \\
\hline $\begin{array}{l}\text { Institutes with nursing managers } \\
\text { involved in HSSR }\end{array}$ & $0(0 / 14)$ & 50 & $64.3(9 / 14)$ \\
\hline $\begin{array}{l}\text { Institutes with nursing HSSR studies } \\
\text { approved in the 2011 PRI call for } \\
\text { proposals* }\end{array}$ & $0(0 / 14)$ & 50 & $14.3(2 / 14)$ \\
\hline $\begin{array}{l}\text { Institutes including HSSR in nursing } \\
\text { scientific events. }\end{array}$ & $0(0 / 14)$ & 50 & $64.3(9 / 14)$ \\
\hline
\end{tabular}

HSSR: Health systems and services research

PRI: Scientific-technical program area

* In 2011 PRI activities were curtailed, making it impossible to meet this goal at the branch level, therefore it was not included among success criteria. applied, which was considered effective if targets were met for all results indicators.

\section{RESULTS}

Characterization The bibliometric study identified 2081 articles on the results of research conducted by nurses; of these, 185 ( $8.9 \%$ of the total) dealt with HSSR, and 174 of these were in international journals. Topics most commonly addressed were: nursing care quality assessment (45 articles, 24.3\%), patient satisfaction (26 articles, $14.1 \%$ ), and nurses' job satisfaction (19 articles, 10.3\%). No study was found on health situation analysis methods. Revista Cubana de Enfermería published 198 nursing research articles, of which 11 (5.6\%) dealt with HSSR. The most common topics were: nursing care quality assessment (4 articles, $36.4 \%$ ) and patient satisfaction (3 articles, 27.3\%).

Situation analysis Questionnaire results revealed poor knowledge about HSSR among the majority of respondents, as well as lack of research teams in the institutes and failure to apply research findings (Table 1 ).

The focus group identified three categories of issues related to nursing HSSR:

- Nurses' knowledge about HSSR. While nurses had a positive opinion of HSSR, they had no clear concept of it. They associated it strongly-indeed, virtually exclusively-with service quality evaluation. Participants recognized HSSR's usefulness in improving quality of care and developing the nursing profession, but most failed to see that its results had implications beyond health services quality.

- Reasons for conducting HSSR. Three were identified: development of nursing science, personal motivation and reshaping the image of the nursing profession.

- Effect of institutional environment. Most concurred that institutes can be influential in promoting HSSR if they foster a positive research climate. Participants noted the need to link HSSR with the institutes' missions, taking advantage of their trained personnel and creating incentives for investigators.

Intervention implementation Orientation workshops. Twelve orientation workshops were held, for the 32 selected nursing managers and the 105 nurses in the research teams. Thirteen such teams were formed to study the problems identified, led by nursing managers and comprised of participating professionals from the institutes.

Based on analysis of the institutes' inventory of problems identified in nursing services, topics lending themselves to research were selected, namely: patient satisfaction; the quality of nursing in neurology, gastroenterology, pediatric cardiology, and orthopedic services; nursing functions in ophthalmology, hematology, neurology, pediatric cancer and gastroenterology services; and job satisfaction among nurses.

Design workshops. There was research team attrition between the orientation and design workshops, with nine of the original fourteen institutes sending research teams to the latter. Some insti- 
tute research teams presented more than one project, for a total of thirteen.

Due to the participatory nature of the intervention, two additional activities not mentioned in the initial proposal were included: a workshop on data collection instrument design (a need identified in the first design workshop) and a workshop on scientific writing (identified in the results of the diagnostic questionnaire).

Followup workshops. There was no further research team attrition between the design and followup workshops. Thirteen projects designed to address the following themes in institute nursing services were approved by their respective scientific committees: 1) quality of nursing care for patients with cerebrovascular disease, Neurology and Neurosurgery Institute; 2) patient satisfaction with care, Endocrinology Institute; 3) quality of nursing care, William Soler Children's Heart Center; 4) nursing functions in ophthalmology services, Ramon Pando Ferrer Ophthalmology Institute; 5) quality of nursing care, Ramon Pando Ferrer Ophthalmology Institute; 6) quality of nursing care, Gastroenterology Institute; 7) nursing functions in hematology services, Hematology and Immunology Institute; 8) quality of nursing care in the cardiovascular surgery unit, William Soler Children's Heart Center; 9) nursing functions in neurology services, Neurology and Neurosurgery Institute; 10) nursing functions in pediatric cancer services, National Oncology \& Radiobiology Institute; 11) nursing functions in gastroenterology services, Gastroenterology Institute; 12) quality of nursing care in outpatient, preoperative and postoperative services, Frank País Orthopedics and Traumatology Institute; and 13) nurses' job satisfaction, Nephrology Institute.

Evaluation Post-intervention data collection showed changes in participants' levels of knowledge of HSSR-an increase in good and fair levels, with all nursing managers achieving at least fair knowledge-and that it was possible to establish research teams, conduct research and disseminate findings to decisionmakers and other revelant parties.

Research teams were formed to conduct HSSR in all institutes at the design workshops, but five institutes did not proceed to the design phase, although they had identified researchable problems. At the end of the intervention there were nine institutes with nursing HSSR research teams, $64.3 \%$ of total.

Following the intervention, all indicators of expected results were fulfilled, exceeding their baselines and meeting targets, with the exception of proportion of projects approved in the PRISS call for proposals (Table 1 ).

Research findings were presented in scientific research fora held at the nine institutes with completed projects. Evaluation results were shared with study participants and DNE.

\section{DISCUSSION}

The essence and foundation of the nursing profession is patient care, which may explain why nurses do not seem to be persuaded of the salience of HSSR. According to Alarcón, research articles published can be considered indicators of a science's output.[25] For example, the framing of the problem and statement of objectives show the transformation of a phenomenon from reality into a scientific phenomenon, whose interactions reveal the complexity and limits imposed on the topic by the investigator. Selection of subjects and units of analysis indicates the discipline's objects of concern. Finally, the methods and design reveal the paradigms and strategy through which the science develops its knowledge.[25] Nursing is a science based on professional practice; thus, the orientation of the publications identified is largely in this direction, rather than examining the systemic context in which nurses practice.

We found three major areas under which nursing research can be classified: patient perceptions, beliefs, knowledge and valuesconsistent with the profession's focus on providing good care that is relevant to its social and cultural context; prevalence and incidence of health problems, indicators of population health status; and evaluation of nursing competencies. Ergul's 2010 examination of articles in six nursing journals also noted the thematic primacy of care delivery.[26]

All of the above explains why the majority of articles published by nurses address these topics. Our initial literature review found few references to studies focusing on HSSR as such. The low levels of HSSR knowledge and output observed could be explained in part by nursing's theoretical and practical focus on individual care and nurses' skepticism about the usefulness of HSSR and in part by the fuzziness of the boundaries of HSSR, in which almost any topic could fit, depending on the researcher's approach.[10]

For example, quality-of-care assessment is one of the ways the profession directly evaluates various aspects nursing care. When nursing services are evaluated, three components are taken into account, any of which could be addessed with an HSSR approach: structure (including organization and resources), competencies and patient satisfaction, the latter traditionally considered the most important indicator by the profession. Thus, a 2002 study in Sweden showed that unfavorable patient opinions discovered through quality assessment studies translated into corrective actions in nursing practice.[28]

The American Nurses Association considers patient satisfaction to be the most faithful indicator of quality of nursing care.[29] Several studies have shown that nursing care is a determinant of overall patient satisfaction at time of discharge.[30-32] While we agree that it is important to gauge patient satisfaction with nursing care, it is not the only quality indicator. Furthermore, studies of patient satisfaction isolated from other quality dimensions tend to overvalue patient perceptions and undervalue professional competencies of which patients are not always aware.

Studies on nurses' job satisfaction, on the other hand, are conducted because of a link between job satisfaction and good performance[33] and the hope that good performance will translate into lower costs. Nurses' job satisfaction is one of the indicators most often cited by international organizations that set norms for professional practice. Yet, one literature review found much of the research on this topic is not aimed at finding solutions to nurses' sources of dissatisfaction.[34] These results imply a need for research using causal models that enable information to be integrated and contribute to staff retention. In his meta-analysis of studies on this issue, Zangaro established associations among job satisfaction, job stress, autonomy and nurse-physician collaboration; these findings support the importance of studying factors that affect nurses' job satisfaction, with a view to improving it.[35] 
The relative absence in nurses' research of health situation analysis may be due to its population focus; this level of analysis is still a challenge for nurses. In this sense, our findings are consistent with the current HSSR situation in Cuba and internationally. The Alliance for Health Policy and Services Research stresses the need to focus on less developed lines of research such as access and equity.[36]

Nurses' dearth of knowledge about conducting HSSR has been analyzed by this author in other publications, which attribute it, among other things, to the fact that there is no clear understanding of its potential contribution to caregiving, the essence of the profession.[10] This problem was also identified in a study conducted in Andalucia, which confirmed the scarcity of projects headed by nurses.[37] Another Spanish study in Barcelona found insufficient research on nursing, and within what was identified, a preponderance of individual nursing care as a topic and of poor quality compared to research by other professional groups. This was explained by lack of a research tradition and training in research methods, since academic nursing is relatively new.[38]

The intervention can be considered effective in developing nurses' research skills and HSSR capacity at participating institutes. Only the target for proportion of projects approved in the PRISS call for proposals was not met, because changes in Cuba's research policies and reorganization of the science and technology system imposed limits on ministerial PRI projects in order to focus more on developing institutional capacities.[39] The research team therefore decided that approval of HSSR projects by institutes was sufficient to define a satisfactory result.

The effectiveness of educational strategies in developing research skills at the individual level in nursing has also been demonstrated by Edwards, who studied nine initiatives of this type throughout the world and found that educational initiatives in which nurses are actively involved in selecting the issues to investigate makes them more likely to become involved in research.[40]

In 2010, the French Nursing Research Association reported on a multicenter study involving 32 countries from all regions. Investi- gators found that capacity building through research training was one of the most frequent steps taken by participating countries to remedy deficiencies in nursing education.[41] Wietrich confirmed the lack of research training in a study of nursing students in Lyon. [42] Purkis also found that linking capacity building in research with practice in care settings helps increase nurses' motivation for research.[43] The importance of the type of intervention described here stems from the fact that it identifies gaps in nurses' research training, the first step towards filling them.

These studies support the effectiveness of strategies such as ours in promoting nurses' involvement in research. Strategy implementation yielded some lessons: addressing problems identified by nurses themselves provides incentive to conduct HSSR, as does collective knowledge-building through the workshops. Involving institutes' senior nursing managers in HSSR contributes to results application, since they become familiar with the research process and better understand significance of findings. Research team attrition is an issue to bear in mind in future interventions.

This study was conducted in national research institutes that are not representative of most health care delivery institutions, constituting a limitation, since these institutes' main objectives already include conducting research in the context of clinical care, thus possibly biasing results. However, such interventions can be replicated in other institutions or at other levels of health care, as long as these start with an initial situation analysis.

Our study's importance lies in the fact that it enabled nurses to conduct HSSR, created research teams and linked senior managers to the research process to tackle problems identified in nursing services. It is recommended that similar interventions be undertaken at other levels of care to promote HSSR by nursing professionals.

\section{CONCLUSIONS}

A systematic strategy to build nursing HSSR capacity can be effective in motivating nurses to become involved in this type of research and in developing institutional support for it, fostering compliance with Cuban and international professional development priorities for nursing and creating the potential to contribute findings to improved health care delivery. $-1 /$ -

\section{REFERENCES}

1. Rojas F. Salud Pública. Medicina Social. Havana Editorial Ciencias Médicas; 2009. p. 24. Spanish.

2. Funciones esenciales de la salud pública. Fortalecimiento de los Sistemas de Salud en América Latina y el Caribe [Internet]. Washington: Pan American Health Organization; 2008 [cited 2010 Feb 12]. Available from: http://www.paho.org/ spanish/dpm/shd/hp/FESP.htm. Spanish.

3. Frenk J. La nueva Salud Pública. In: La crisis de la Salud Pública: reflexiones para el debate. Washington: Pan American Health Organization; 1992. Spanish.

4. Carel J. Human resources for Health research. Proceedings of the Symposium at the Swiss Tropical Institute; 2007 March; Switzerland.

5. Lansang MA, Dennis R. Building capacity in health research in the developing world. Bull World Health Organ. 2004 Oct;82(10):764-70.

6. Nchinda TC. Research capacity strengthening in the South. Soc Sci Med. 2002 Jun;54(11):1699-711.

7. Strategic directions for strengthening nursing and midwifery services 2011-2015 [Internet]. Gen- eva: World Health Organization. Department of Human Resources for Health; 2011 Jan [cited 2011 Jun 13]. 31 p. Available from: http://whqlib doc.who.int/hq/2010/WHO_HRH_HPN_10.1 _eng.pdf

8. Martínez N, Torres M, Urbina O, Otero M. Los Proyectos de ISSS de Enfermería para la toma de decisiones. Una mirada reflexiva. Rev Infodir. 2008;(6). Spanish.

9. Strengthening of research on health systems and services (HSSR) within PAHO's technical cooperation. [Internet]. Washington: Pan American Health Organization; 1998 May [cited 2012 May 17]. 13p. Available from: http://www.paho .org/English/HDP/HDR/doc456.pdf

10. Martínez N, Torres M, Urbina O, Otero M. La brecha entre Investigación en Sistemas y Servicios y la práctica de enfermería. Posibles causas. Rev Cubana Enfermer. 2010;26(3):161-8. Spanish.

11. Rojo N, Caraballoso M, Martínez S, Pérez B, Pérez J, Resik P, et al. Programa Ramal Investi- gación en Sistemas y Servicios de Salud. Documento Rector 2003-2006. Havana: National School of Public Health (CU); 2003. Spanish.

12. Caraballoso M, Rojo N, Martínez S, Pérez B, Bayarre $\mathrm{H}$, Hernández E. Proyecto Estrategia de capacitación para las investigaciones en servicios y salud en Cuba. Havana: National School of Public Health (CU); 2006. Spanish.

13. Alliance for Health Policy and System Research. Building and Strengthening Partnerships - Annual report 2010. Geneva: World Health Organization; 2010.

14. Silva LC. Diseño razonado de muestras y captación de datos para la investigación sanitaria. Madrid: Ediciones Díaz de Santos, S.A; 2000. 332 p. Spanish.

15. Martínez N. Las Investigaciones en sistemas y servicios de salud por enfermería en las revistas científicas. Rev Cubana Enf. 2011;27(3):228-38. Spanish.

16. Callejo J. Introducción al proceso de análisis e interpretación. In: El grupo de discusión: introducción a una práctica de investigación. Barce- 
Iona: Colección Ariel Ciencias Políticas; 2001. p. 147-59. Spanish.

17. El análisis de los datos cualitativos. In: Ulin PR, Robinson ET, Tolley EE, editors. Investigación aplicada en Salud Pública. Métodos cualitativos. Washington DC: Pan American Health Organization; 2006 Apr. 286 p. Spanish.

18. Generalidades. In: Bayarre Vea H, Pérez Piñero J, Castañeda Abascal I, Ranero Aparicio V, editors. La Investigación en Sistemas y Servicios de Salud. Material Docente de la Residencia de Bioestadística. Havana: National School of Public Health (CU); 2005. Spanish.

19. Bacallao Gallestey J. Fragmentos del dossier bibliográfico del módulo Investigación Educacional. Havana: National School of Public Health (CU); 2002. Chapter 3: El proyecto científico. p. 15-8. Spanish.

20. El protocolo de la investigación. In: Bayarre Vea $\mathrm{H}$, Horsford Saing R, editors. Métodos y técnicas aplicadas a la investigación en Atención Primaria de Salud. Havana: Ediciones Finlay; 2000. p. 61-8. Spanish.

21. Pérez Piñero J. El proceso de investigación científica. Havana: National School of Public Health (CU); 2002.

22. Artiles L, Otero J, Barrios I. Metodología de la investigación para la Ciencias de la Salud. Havana. Editorial Ciencias Médicas; 2008. p. 104-135. Spanish.

23. Torres E. Metodología para definir funciones profesionales (DEFUN). Rev Cubana Salud Pública. 2008;34(4). Spanish.

24. Carnota O. Biblioteca virtual para formación post graduada directivos del sector salud. Versión 2007. [CD-ROM] Havana: CEDISAP; 2007. Spanish.

25. Zall J, Rist R. Ten steps to a results- based monitoring and evaluation system. 3rd ed. Washington: World Bank; 2010.
26. Alarcón A, Astudillo P. La investigación en enfermería en revistas latinoamericanas. Rev Ciencia y Enfermería. 2007;XIII(2):25-31. Spanish.

27. Ergul S, Ardahan M, Temel AB, Yildirim BÖ. Bibliometric review of references of nursing research papers during the decade 1994-2003 in Turkey. Int Nurs Rev. 2010;57(1):49-55.

28. Johansson P, Oléni M, Fridlund B. Patient satisfaction with nursing care in the context of health care: a literature study. Scand J Caring Sci. 2002 Dec;16(4):337-44.

29. Schreiber C. A closer look: Patients explain what they think makes excellent nursing. Health Week. 1999;7:14-5.

30. Patient Satisfaction Survey. South Bend: Press Ganey Association; 2002.

31. Abramowitz S, Coté AA, Berry E. Analyzing patient satisfaction: A multi-analytic approach. QRB Qual Rev Bull. 1987 Apr;13(4):122-30.

32. Greeneich D. The link between new and return business and quality care: patient satisfaction. ANS Adv Nurs Sci. 1993 Sep;16(1):62-72.

33. Maslow AH. Motivation and Personality. 2nd ed. New Tork: Harper \& Row; 1970. 369 p.

34. Lu $H$, While $A E$, Barriball $K L$. Job satisfaction among nurses: a literature review. Int J Nurs Stud. 2005 Feb;42(2):211-27.

35. Zangaro GA, Soeken KL. A meta-analysis of studies of nurse's job satisfaction. Rev Nurs Health. 2007 Aug;30(4):445-58.

36. Alliance HPSR. Strategic Plan 2011-2015 Bridging the worlds of research and policy. Geneva: World Health Organization; 2011. 32 p.

37. Díaz Benavente M. Estructuras de investigación de Enfermería en Andalucía y perspectivas de futuro [Internet]. Rev Salud y Cuidados. 2003 May [cited 2007 Jul 20];23(5). Available from: http://www.saludycuidados.net/numero5/invesandalucia1.htmISSN 1578-9128. Spanish.
38. Sánchez M. Análisis de los proyectos de investigación de enfermería presentados al FIS desde el año 1989 al 1992. Rev Enf Clín. 1995;5(2):6971. Spanish.

39. Resolución 44 / 2012 [Internet]. Havana: Ministry of Science Technology and the Environment (CU); 2012 Feb 27 [cited 2012 May 20]. 10 p. Available from: http://files.sld.cu/sccs/ files/2012/03/ministerio-de-ciencia-tecnologia-y -medio-ambiente-res-4412.pdf. Spanish.

40. Edwards N, Webber J, Mill J, Kahwa E, Roelofs $\mathrm{S}$. Building capacity for nurse-led research. Int Nursing Rev. 2009 Mar;56(1):88-94.

41. Formarier M. Réflexions sur la recherche en soins infirmiers aujourd'hui. [Internet]. Rech Soins Infirm. 2010 Mar [cited 2010 Nov 23];100. Available from: http://fulltext.bdsp.ehesp.fr/ Rsi/100/111.pdf. French.

42. Wietrich L, Regnier JC. L'initiation a la recherche en soins infirmiers: outil de construction de l'identité professionnelle infirmière. Rev Rech Soins Infirmières. 2005 Mar;80(3):87-103. French.

43. Purkis J, Jackson JA, Hundt G, Stockman C. Increasing nursing research capacity in the workplace. Nurs Times. 2008 Sep;104(37):28-31.

\section{THE AUTHOR}

Nelcy Martínez Trujillo (nelcynan@infomed. sld.cu), nurse with a master's degree in public health. Associate professor, National School of Public Health, Havana, Cuba.

Submitted: February 20, 2012

Approved for publication: July 7, 2012

Disclosures: None

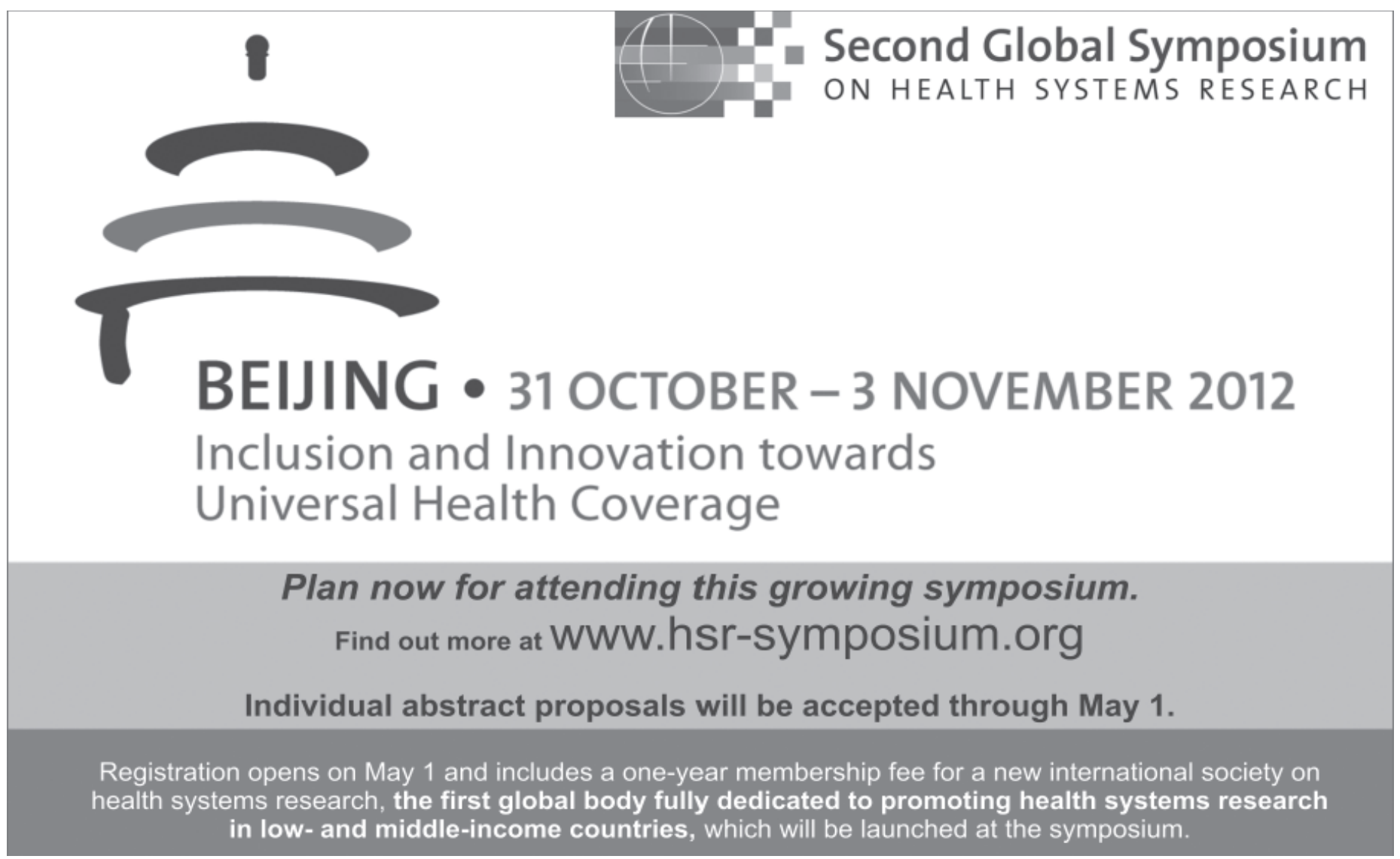

